\title{
Apostillas en torno al discurso periodístico sobre delito e inseguridad: figuraciones de las víctimas y los victimarios en noticieros argentinos de televisión abierta
}

\author{
Natalia Raimondo Anselmino' \\ http://orcid.org/0000-0001-7217-8754 \\ Natalia Aruguete" \\ https://orcid.org/0000-0002-1571-9224 \\ Francisco Hernando Arri"l' \\ https://orcid.org/0000-0002-8946-9870 \\ I - Conicet. UNR. UAI \\ Rosario, Argentina \\ II - Conicet. UNQ \\ Buenos Aires, Argentina \\ III - Universidad del Salvador \\ Buenos Aires, Argentina
}

Resumen: Este artículo es producto de las primeras aproximaciones a los modos en que son figurados los personajes centrales de las noticias televisivas sobre delito e inseguridad en canales de televisión abierta en Argentina y su construcción en el relato como víctimas o victimarios. Se trata de un conjunto de inferencias iniciales elaboradas en el marco de un proyecto mayor titulado "De la propiedad a la recepción. Estudio integral del circuito productivo de las noticias sobre delito e inseguridad en los noticieros televisivos de mayor audiencia de la Argentina". Se parte de la idea de figuración propuesta por Traversa (1997) y releída por Fernández y Tobi (2009), para poder identificar cadenas de operaciones respecto de un determinado régimen discursivo como construcción. Desde esta mirada, es posible reconocer ciertas recurrencias significativas en el modo en el que son figurados las víctimas y los victimarios en los discursos periodísticos televisivos que forman parte del corpus bajo estudio. 
Palabras clave: discurso periodístico; figuraciones; víctimas y victimarios; noticieros argentinos.

\begin{abstract}
Apostilles around the journalistic discourse on crime and insecurity: figurations of the victims and the perpetrators in Argentine television news broadcasts - This article is the product of the first approaches to the ways in which the central characters of the television news about crime and insecurity in open television channels in Argentina and its construction in the story as victims or victimizers are figured. It is a set of initial inferences drawn up within the framework of a larger project entitled "From ownership to reception. Comprehensive study of the productive circuit of the news about crime and insecurity in the television news programs with the highest audience in Argentina ". It starts from the idea of figuration proposed by Traversa (1997) and re-read by Fernández and Tobi (2009), in order to identify chains of operations with respect to a specific discursive regime as a construction. From this point of view, it is possible to recognize certain significant recurrences in the way in which victims and perpetrators are figured in television journalistic discourses that are part of the corpus under study.
\end{abstract}

Keywords: journalistic discourse; figurations; victims and victimizers; Argentine newscasts.

\title{
Presentación
}

Desde finales del siglo XX se asiste a un cambio significativo en la preocupación por el crecimiento del delito que se manifiesta en la opinión pública, aunque también en las agendas de cuestiones políticas y, sobre todo, en las coberturas mediáticas (DAMMERT, 2010; KESSLER, 2009; SOZZO, 2016). En cuanto a la presentación mediática de las noticias referidas a la inseguridad ${ }^{1}$, tanto en la prensa gráfica como en los medios audiovisuales se produce una transición de tipo cuantitativa como cualitativa (FOCAS; KESSLER, 2015); en otras palabras, esto implica no solo un crecimiento en términos de cantidad de noticias sino, también, ciertos cambios ligados a las características de las mismas.

Por otra parte, los vínculos observados entre el consumo de noticias policiales y el temor al delito permiten inferir que los medios de comunicación son actores centrales. Los mismos funcionan como victimizadores indirectos que potencian el miedo al delito (KESSLER, 2005) al tiempo que cristalizan estereotipos de delincuentes y construyen una espacialidad y una temporalidad singulares (CALZADO, 2012, 2015; KESSLER, 2013) que consolidan la "línea divisoria entre un 'nosotros' merecedor de la seguridad, encarnado en el 'buen ciudadano' o el 'vecino', y un 'otro', asociado al joven pobre de barrios marginales" (ARUGUETE et al., 2018, p. 232). El discurso de información sobre el delito, a su vez, suele construirse en referencia a un pasado mítico de seguridad y libertad que se contrapone a un presente de riesgos y de miedos.

La tesis de que los medios de comunicación son los responsables del sentimiento de inseguridad ha sido puesta en cuestión a partir del análisis de otras variables ligadas al entorno, la cultura y la experiencia. No obstante, existe consenso acerca de que estos

1 Entendida, siguiendo a Kessler (2009), como una sensación de indefensión de los individuos contra una amenaza aleatoria, que opera con autonomía relativa respecto de los hechos delictivos. 
desempeñan un rol significativo en la creación de un estado de riesgo que trae aparejadas demandas de mayor control social y punitividad (ENTEL, 2007; KILLIAS, 1991; MARTINI, 2012).

La investigación - que aún se encuentra en ejecución - en el marco de la cual se han producido las inferencias presentadas en este texto ha sido gestada ante la evidencia de que existen pocos estudios que aporten una visión integral que incluya las distintas instancias del circuito productivo de las noticias sobre delito, violencia e inseguridad en los noticieros televisivos. De allí que este artículo se inscriba en un proyecto más general² que analiza cómo los medios de comunicación audiovisuales en Argentina producen y ponen en circulación dicha información, desde un abordaje que integra: las condiciones de propiedad de la producción mediática, las rutinas productivas, el contenido noticioso y su construcción discursiva, así como la recepción de este tipo de discurso.

En este artículo se analizan, particularmente, ciertas recurrencias significativas en el modo en que son figurados los personajes centrales de las notas televisivas que versan sobre delito e inseguridad: las víctimas y los victimarios. Sin la intención de producir inferencias generalizables sobre el conjunto de las noticias sobre delito, violencia e inseguridad, las reflexiones aquí desarrolladas procuran, más bien, ilustrar en el marco de un corpus menor, ciertas configuraciones discursivas que suelen caracterizar a este tipo de productos mediáticos.

\section{Notas sobre el procedimiento analítico y el corpus bajo estudio}

Como se ha dicho, este trabajo es parte de un proyecto de investigación mayor en el marco del cual se estudia un conjunto de noticias del ámbito nacional sobre delito, violencia e inseguridad puestas al aire en los noticieros transmitidos, durante el horario central (prime time), por los canales 11 y 13 del Área Metropolitana de Buenos Aires (AMBA); 10 y 12 de Córdoba; 3 y 5 de Rosario, y 9 y 7 de Mendoza, en la semana que va del 1 al 5 de agosto de 2016. Los canales mencionados pertenecen a los cuatro conglomerados urbanos más poblados de la Argentina y fueron seleccionados por el volumen de su audiencia, con excepción del Canal 10, cuya elección se debió a criterios de diferenciación ${ }^{3}$. Del total de las notas presentadas a lo largo de cada una de las ediciones de los noticieros comprendidos en el período escogido para la investigación, se decidió analizar, específicamente, tres tipos de géneros periodísticos en particular: los informes, las crónicas y los móviles. Consecuentemente, se obtuvo un corpus que comprende un total de 192 noticias, distribuidas de la siguiente manera: 26 de canal 11; 38, del 13;

2 Proyecto de Investigación Orientada (PIO 2015-2016 CONICET - Defensoría del Público) -dirigido por Gabriel Kessler y codirigido por Natalia Aruguete- y Proyecto de Investigación Científica y Tecnológica (MINCyT) 2015 -dirigido por Martín Becerra: "De la propiedad a la recepción. Estudio integral del circuito productivo de las noticias sobre delito e inseguridad en los noticieros televisivos de mayor audiencia de la Argentina". El mismo cuenta con la participación de investigadores de las universidades nacionales argentinas de La Plata, Quilmes, Rosario, Buenos Aires, Córdoba y las universidades Del Salvador y Austral.

3 Se trata de un canal público que depende de una universidad nacional. 
13, del 10; 6, del 12; 34, del 3; 21, del 5; 29, del 9, y 35, del 7. Asimismo, en tanto esta pesquisa procura integrar diferentes aristas del circuito productivo de las noticias sobre delito e inseguridad articulando perspectivas teóricas diversas, en un primer momento se Ilevó a cabo un estudio sistemático sobre todas las unidades de análisis a partir de una matriz elaborada ad hoc (Cfr. ARUGUETE et al., 2018). Ello hizo posible construir un volumen importante de datos sobre el contenido informativo, pero también comenzar a reconocer ciertas manifestaciones concretas de su puesta en discurso. A partir de allí, se emprendió un análisis pormenorizado sobre la configuración discursiva de un conjunto menor de piezas textuales que comprende una unidad de análisis por cada una de las cuatro localizaciones estudiadas (AMBA, Córdoba, Rosario y Mendoza). A saber:

- Dos jóvenes 'cuidacoches' baleados en el centro de Rosario, emitida por Canal 3 de Rosario el $1^{\circ}$ de agosto de 2016, con una duración de 8 minutos y 53 segundos;

- Vigilaba un super chino y mató a un ladrón, exhibida por Canal 11 de Ciudad Autónoma de Buenos Aires (CABA) el 2 de agosto, con una duración de 4 minutos y 58 segundos;

- Giro en la causa por el femicidio de Carina Drigani, presentada en Canal $10 \mathrm{de}$ Córdoba, también el 2 de agosto y con una duración de 11 minutos y;

- Un policía acusado de violencia de género se atrincheró en su casa y se negó a entregarse, difundida por Canal 9 de Mendoza el $1^{\circ}$ de agosto de 2016, con una duración de 18 minutos.

Entre todas las operaciones discursivas ${ }^{4}$ que es posible reconocer en las piezas analizadas, interesan aquí, como ya se ha expresado, aquellas que permiten reconstruir los modos en que son figurados las víctimas y los victimarios de las noticias sobre delito e inseguridad. Se entiende a la figuración siguiendo la idea originalmente propuesta por Traversa $(2009)^{5}$ y en una lectura de esta noción cercana a la planteada por Fernández y Tobi (2009). Se trata, por tanto, de poner el acento en los "modos de semiotización de una entidad identificable" (TRAVERSA, 2009, p.251) — en este caso, tanto en la entidad presentada en calidad de víctima o de victimario - según un determinado régimen discursivo. Vale advertir, asimismo, que dicho análisis no se circunscribe, en este caso, al reconocimiento de operaciones retóricas sino, más bien, considera a la figuración como una noción más general que nos permite alumbrar ciertos aspectos de la configuración discursiva de las noticias estudiadas. Las operaciones que aquí interesan no se restringen, por ello, a aquellas que se materializan a nivel del texto lingüístico. Por el contrario,

4 Según la teoría de los discursos sociales propuesta por Eliseo Verón (1987), las operaciones son siempre operaciones subyacentes, "reconstruidas a partir de marcas inscriptas en la superficie material" (p. 129). Estas marcas son huellas de las condiciones productivas.

5 Esto es, concibiendo a la figuración como un resultado: "una construcción y, como tal, efecto de operaciones de intersección; más precisamente, de cadenas de operaciones, que se sitúan en distintos niveles de organización de los textos" (p. 251). 
se atiende globalmente a la puesta en sentido que toda escena televisada supone (VERÓN, 2001), incluso cuando se trata de discurso periodístico o, más precisamente, de discurso de la información ${ }^{6}$.

En tanto procedimiento centrado en el nivel de la enunciación, se identifican aquellas operaciones enunciativas regulares, es decir, modalidades del discurso cuyo funcionamiento es relativamente constante "y que, en consecuencia, dan cierta estabilidad a la relación soporte/lector" (VERÓN, 2004, p.179). No se trata, entonces, de una mera descripción de las determinaciones lingüísticas sino de la producción discursiva en su vinculación con el campo de las relaciones sociales que han dejado huella en la misma: "lo que interesa al análisis del discurso es la descripción de la configuración compleja de condiciones que determinan el funcionamiento de un sistema de relaciones sociales en una situación dada" (SIGAL; VERÓN, 2008, p.16). Es, por tanto, una práctica analítica a través de la cual se buscan huellas o marcas que reenvíen a un funcionamiento discursivo sistemático. Todo esto se lleva a cabo, en el caso de esta investigación interdisciplinar, en conexión con un proceso inferencial sobre las formas de encuadrar los acontecimientos delictivos y la influencia de las fuentes de información, a partir de la colaboración del framing y el standing ${ }^{7}$.

\section{Algunas figuraciones}

Para poder ilustrar el mencionado procedimiento analítico, se trabajará durante las próximas líneas sobre cuatro de las notas señaladas previamente, mostrando en cada una de ellas cómo es posible identificar el modo en que son figurados tanto víctimas como victimarios.

La primera de las notas - Dos jóvenes 'cuidacoches' baleados en el centro de Rosario - consiste, casi exclusivamente, en un móvil en vivo realizado frente a la puerta del Hospital de Niños "Dr. Víctor J. Vilela", de la ciudad de Rosario. En él, tanto la enviada especial como el presentador (en piso) entrevistan a los padres de dos jóvenes — más precisamente, a la madre de uno y al padre de otro (Imagen 1) - que han sido recientemente baleados y se encuentran internados. En principio, es posible ver cómo a partir de un apelativo ${ }^{8}$ constituido por una palabra compuesta (cuidadoches) se manifiesta

6 Verón (2004) define como discurso de la información a aquel que tiene por objeto a la actualidad -contada, habitualmente, desde un registro impersonal- y debe ser conceptualizado en relación, por un lado, "con la red tecnológica de los medios y con los sistemas de normas que rigen la profesión del periodista y, por otro lado, [con determinadas] modalidades de construcción de un único destinatario genérico, el ciudadano habitante" (p. 196).

7 Framing y frame son dos caras de la misma moneda. El primero alude al proceso integral y activo de producción, circulación y reproducción de significados socialmente compartidos y persistentes en el tiempo. Los frames, presentes en las distintas etapas del proceso comunicacional, son definidos como principios organizadores compartidos socialmente, que trabajan simbólicamente para estructurar el mundo social de modo significativo (Reese, 2007). La noción de standing (FERREE et al., 2002) constituye un aporte novedoso para el Framing, dado que amplía el análisis al reconocer la capacidad de las fuentes de información de obtener crédito en el marco interpretativo dominante en las coberturas (KOZINER 2018).

8 Siguiendo a Adelstein (1996), se entiende por apelativo a todo término del léxico (ya sean estos pronombres personales, nombres propios, cargos o títulos institucionales o sustantivos orientados a manifestar un determinado tipo de relación o parentesco, entre otros) que "es empleado en el discurso para mencionar a una persona" ( $p$. 29). Estos pueden desempeñar el rol de deícticos y tener, también, carácter predicativo -en tanto por medio de ellos es posible "efectuar una cierta predicación explícita" (p. 29)- y evidencian relaciones sociales. 
una operación de asignación de sentido figurado mediante la cual se imbrica el discurso periodístico con expresiones léxicas provenientes de la jerga presente en otros discursos sociales - algo similar a lo que sucede con el calificativo "motochorros" en la segunda noticia analizada. Los jóvenes baleados son figurados como víctimas doblemente víctimas — sobre este tipo de figuraciones también han trabajado Fernández y Tobi (2009, p. 62) —, por su condición marginal y de minoridad y por la desprotección de sus padres: "triste realidad de chicos que pasan mucho tiempo en la calle"; "situaciones muy complejas"; "dos nenes de 15 y 13 años"; "un nene de Cabín 9 y el otro de barrio Tablada"9; "niño de 13 años"; "nenes baleados"; o el empleo del apócope "Leo", en lugar del nombre completo. Los menores, así designados, no son agentes de la acción para el discurso del medio: "fueron baleados"; "uno recibió varios impactos de bala en las piernas y el otro en el abdomen". Como contraparte, del autor de los disparos — un supuesto victimario — nada se sabe; es sólo "un hombre". Por ello, la responsabilidad del padecimiento de los chicos termina siendo atribuida a sus padres e, incluso, la bala funciona, sineqdóquicamente, como agente de la acción en oraciones como las siguientes: "la bala [...] atravesó varios órganos"; "los órganos que atravesó la bala". Los padres, convertidos en responsables, son ubicados discursivamente en el lugar de la impotencia y la ignorancia, sobre todo a partir de lo enunciado por el presentador del noticiero, quien constantemente los interpela, y gesticula con desagrado ante la respuesta de sus entrevistados: "¿Tenés algunos inconvenientes en la crianza"; “iTe consta que son muy amigos"; “Así que no saben ustedes del cuidacoches?"; “¿No sabía, Carla, que su hijo tenía ese amigo?". En términos de framing podría agregarse que la responsabilidad asignada a los padres de las víctimas no es, en este caso, ni social, ni institucional o política sino que es resultado de un encuadre individual. Toda atribución de responsabilidad ${ }^{10}$ - ya sea expresada en términos disposicionales o estructurales - tiene como contracara posibles salidas o resoluciones que se proponen al problema encuadrado.

En este informe, el discurso del medio está atravesado por un sesgo de normalización (BENNETT, 2012), al afirmar, desde lo enunciado por la movilera, que "ha estado interviniendo la Secretaría de Desarrollo Social, hablando con las familias, para volver a escolarizarlos a estos chicos". De este modo, se propone que las instituciones están para hacer que el sistema siga adelante y cumpla sus obligaciones. Para Bennett (2012), la principal consecuencia de una cobertura normalizada es que limita el rango de los modelos aceptables, incluso pensables, para la acción política.

9 Se observa en esta frase un procedimiento de localización geográfica que también ubica a los jóvenes (al menos para el espectador rosarino que puede reconocer dicha asignación) en una zona pobre de esa ciudad.

10 El predominio de ciertos elementos de encuadre en las noticias moldea una determinada realidad: define un problema, le atribuye causas e identifica eventuales responsables, sugiere un remedio para solucionarlo y lo evalúa de acuerdo con un trasfondo moral o esquema de valores (Aruguete, 2019, en prensa). La atribución de responsabilidades analizada en este artículo es tomada de la definición de encuadre propuesta por Entman (1993 y 2004). 


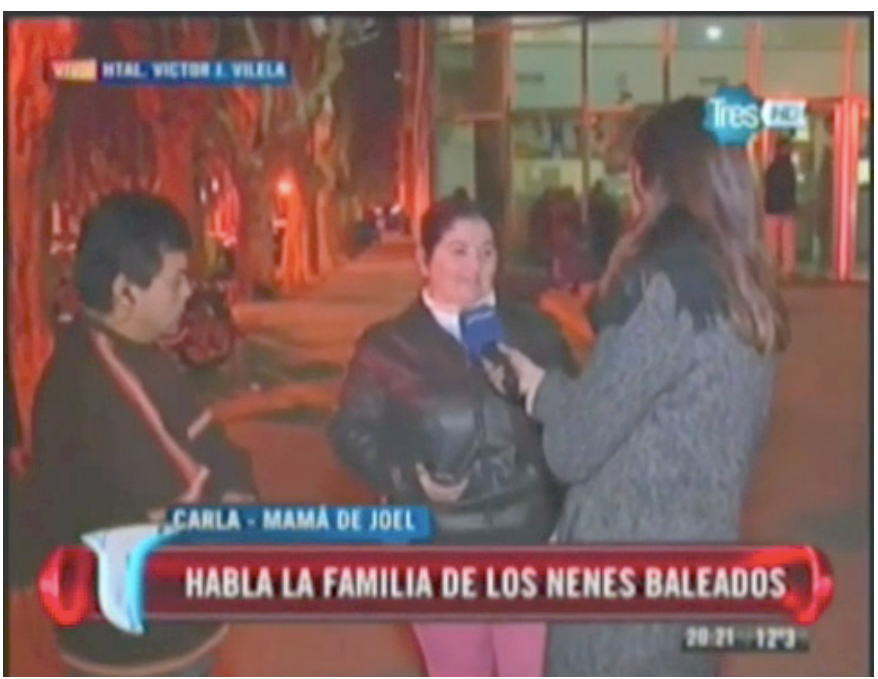

Fig. 1. Captura de TV nota "Dos jóvenes 'cuidacoches' baleados en el centro de Rosario". (Fuente: Canal 3 de Rosario).

En el segundo caso - Vigilaba un super chino y mató a un ladrón —, se presenta un informe sobre el homicidio de un ladrón en ocasión de un intento de asalto a un supermercado de un barrio del conurbano bonaerense. En tanto informe, las imágenes son grabadas - la mayoría de ellas tomadas con la cámara de seguridad del lugar ${ }^{11}$ (Imagen 2) - y, aunque existen diversos testimonios, ninguno es registrado en vivo. En varias de las frases presentes en esta nota se observa la configuración de un universo dicotómico bien/ mal o legalidad/ilegalidad, que promueve un discurso polarizado. El acontecimiento es identificado por el medio como "Enfrentamiento entre el ladrón y el policía": de un lado, la figura del policía que cumplió con su deber; del otro lado, la figura del delincuente. Mediante esta dicotomía, "el enunciador se alza con la autoridad para trazar la línea que separa el bien del mal, lo comprensible de lo irracional" (FERNÁNDEZ; TOBI, 2009, p. 61). Por otra parte, las acciones realizadas por el policía - quien, principalmente, es figurado mediante su identificación sociológica-laboral ${ }^{12}$, aunque también es calificado a través de los apelativos "uniformado" y "custodio" — están, generalmente, en voz activa pero son atenuadas

11 El recurso de la constante reiteración de las imágenes captadas por la cámara de seguridad son, en esta nota, parte de una retórica hiperbólica reforzada, también, desde el plano lingüístico verbal: se trata de "imágenes altamente impactantes", según los dichos de uno de los presentadores.

12 Puede decirse que este es un procedimiento habitual en el discurso de la información sobre delito e inseguridad en Argentina. Es usual advertir que cuando los victimarios (incluso en el caso de delitos graves como el homicidio) provienen de sectores socioeconómicos medios o medios altos los apelativos que se emplean para designarlos son, prevalentemente, aquellos que los identifican en su rol profesional o laboral (es decir, los ubica en el "mundo del trabajo"), algo que no sucede cuando quien comete el delito es pobre. Algunas reflexiones sobre ello pueden leerse en Aruguete y Raimondo Anselmino (2018). Estos procedimientos se observan a lo largo de la descripción de las distintas notas estudiadas. 
con frases como: "terminó encontrándose ante este intento de robo y matando al ladrón"; "termina en un fuego cruzado". La persona asesinada es calificada como "ladrón" — un apelativo de identificación moral —, no como víctima de la acción violenta; es designado como "delincuente", "delincuentes armados" o "motochorros", pero no con su nombre propio. Del "otro ladrón" sólo se informa que tiene 27 años sin emplear un apelativo que lo ubique en alguna franja etárea (joven, por ejemplo), como suele suceder en otros casos. Singularmente, el término "homicidio" no aparece en el discurso del medio, ni en los dichos del periodista-especialista en piso que utiliza el eufemismo "esta situación" para referirse al acontecimiento, ni en el zócalo que reza "Asalto y drama". De este modo, la acción del policía es presentada como consecuencia del enfrentamiento provocado por el muerto ("el delincuente apuntó primero"). La atenuación del accionar del policía es, a su vez, acompañada por el empleo de términos del campo semántico (ADELSTEIN, 1996) propio del discurso policial: "uniformado"; "el efectivo se identificó". He aquí un encuadre individual que propone como único responsable al ladrón, al interior de un discurso descontextualizado y deshistorizado, y repercute de modo directo en las actitudes punitivas (SOTO NAVARRO, 2005, p. 81), reforzando el universo dicotómico antes aludido.

Esta noticia presenta dos tipos de víctimas: por un lado, los comerciantes - "ya fueron robados", "habían vivido dos episodios", "sufren amenazas", "están asustados" y "viven con problemas" - y, por otro lado, "todos". Los comerciantes — término de identificación sociológica-laboral — son figurados centralmente a partir de su origen étnico: "la china"; "comerciantes chinos"; "comerciantes de origen chino", manifestándose, así, una estrategia de distanciamiento étnico. Esos comerciantes son configurados como un otro distinto (distancia social) a quienes proveen su testimonio en calidad de vecinos, algo marcado sobre todo por el empleo del pronombre personal ellos: "ellos no dicen nada"; "ellos no hablan"; "ellos tienen miedo". Es interesante la utilización del pronombre indefinido uno en el testimonio de un vecino, el mismo no sólo es usado con referencia al yo que habla sino, también, a un general. Sintagmas como "uno está ahí comprando" o "por ahí le toca a uno" permiten concluir con "es un peligro para todos".

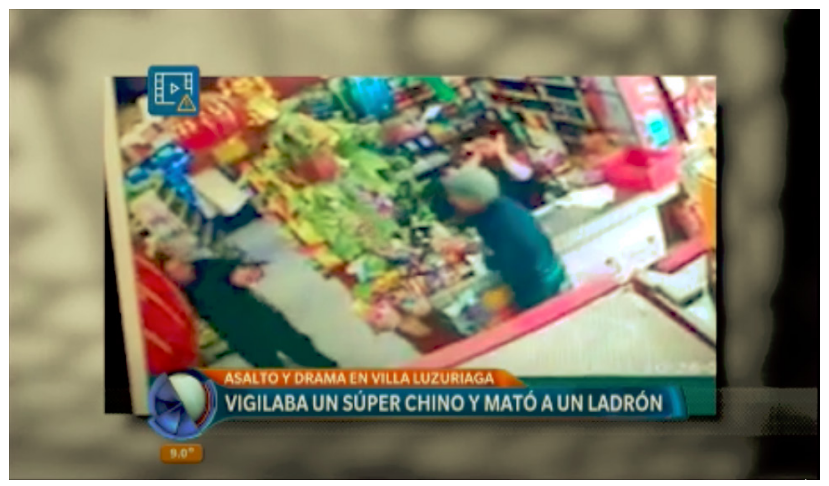

Fig. 2. Captura de TV nota Vigilaba un super chino y mató a un ladrón. (Fuente: Canal 11 de CABA). 
En la tercera nota - Giro en la causa por feminicio de Carina Drigani — se recogen los últimos avances de una causa de femicidio ocurrido en Icho Cruz, localidad serrana de la provincia de Córdoba, mediante un informe que incluye un móvil en vivo. Allí, los personajes — todos de clase media — aparecen calificados con nombre y apellido. Como se observa en la nota anterior, se configura un universo dicotómico bien/mal que puede verse tanto en la no problematización de los antecedentes de violencia del ex marido de la mujer asesinada, Daniel Baretta (quien cuenta "este lado de la verdad", según la movilera), como en momentos donde el bien y el mal aparecen representados con imágenes: la foto de identificación de la víctima del femicidio, Carina Drigani, que se funde con la foto de identificación del victimario, Hugo Salas. La presentación negativa del victimario se manifiesta también mediante el uso de pronombres demostrativos como "esta persona", "este Hugo Salas". Según el discurso del medio, Carina no es la única víctima e, incluso, es el sujeto pasivo o paciente en las frases en las que se la refiere. Es decir, es el sujeto que padece la acción generalmente expresada en voz pasiva: "Carina fue asesinada"; "mujer que fue encontrada muerta". En el discurso de la movilera, Carina aparece como un agente secundario: "la mamá del nene". El ex esposo ocupa, también, el lugar de víctima: "uno de los perjudicados"; "la pasó y la penó"; "una persona que no tenía nada que ver con el asesinato". Muchas de las acciones que dicho sujeto realiza son expresadas, a veces, en voz pasiva o matizadas por verbos modales que indican obligación impuesta desde fuera: "se tuvo que comer un montón de años en la cárcel". Asimismo, cuando la voz en off advierte que Baretta "había sido detenido [...] por los hechos anteriores pero no por la muerte de Carina", puede observarse un procedimiento de concesión aparente. Según Van Dijk, Ting-Toomey, Smitherman y Troutman (2000), esta operación puede encontrarse cuando "reconocemos que hicimos algo malo (o que ellos hicieron algo bueno), pero luego disculpamos o minimizamos nuestra mala acción" (p. 248). Las acciones negativas que se le atribuyen a Baretta están expresadas con el verbo en potencial: "habría recibido".

En esta nota las fuentes de información evocadas son predominantemente oficiales/ institucionales, "con poder para afectar el resultado de un evento noticioso en desarrollo" (BENNETT, 1996, p.376). Visto desde la noción de indexing, las fuentes oficiales/ institucionales suelen alcanzar, al interior del discurso de los medios, mayor nivel de standing, por cuanto tienen la capacidad de condicionar la definición que el discurso mediático da al acontecimiento. Como mencionamos anteriormente, el standing (crédito, en su traducción al español) da cuenta de la capacidad de las fuentes de información de obtener de crédito, aportando una definición de los hechos que coincide con el marco interpretativo dominante en las coberturas. Para constatar el crédito de las fuentes en el discurso de información es importante que estas no solo sean citadas y obtengan visibilidad en los textos sino, además, que no se emitan valoraciones negativas sobre sus expresiones y, sobre todo, que no se desacredite su definición del asunto tratado (KOZINER, 2018). 


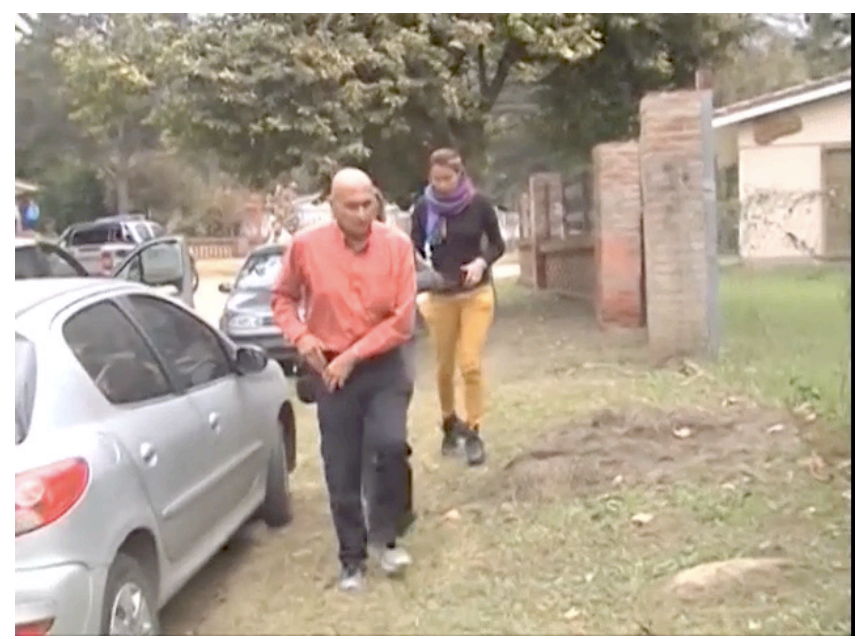

Fig. 3. Captura de TV Giro en la causa por femicidio de Carina Drigani.

(Fuente: Canal 10 de Córdoba)

La cuarta y última nota elegida - Un policía acusado de violencia de género se atrincheró en su casa y se negó a entregarse — podría inscribirse en la categoría breaking news (noticia en desarrollo):

Las breaking news están allí porque transmiten cierta sensación, y no por la importancia de su contenido. Su función tiene poco que ver con comunicar a las audiencias los acontecimientos significativos del día — están allí como un símbolo de novedad [...] Si las audiencias realmente quieren constantes publicaciones de breaking news — y de eso hay poca evidencia —, tiene más que ver con una demostración semiótica de inmediatez que con estar bien informado (LEWIS; CUSHEON, apud DESIDERI; SALAVERRÍA, 2015, p. 151).

En este caso, la noticia está compuesta por tres fragmentos de discurso: una breve presentación al inicio de esa edición del noticiero dentro de los títulos de "último momento" con "información en pleno desarrollo"; el despliegue central de la noticia producido en ocasión de un móvil en vivo y; una especie de cierre y resumen del caso hacia el final de la emisión, también desde el lugar de los hechos. En tanto breaking news, la nota comienza a construirse mediante una conversación telefónica entre la movilera y el presentador del noticiero en piso que da paso, minutos más tarde, al móvil propiamente dicho. Móvil que, incluso, el medio decide poner al aire sin tener información clara y completa sobre el acontecimiento ${ }^{13}$ que acaba de ocurrir: un "policía

13 Es recién en el último episodio de la nota que se presenta casi al cierre del noticiero donde la movilera corrige la información que previamente había brindado. Por ejemplo, se explica entonces que el lugar donde se había atrincherado el "efectivo policial" era, en realidad, la casa de una amiga de la víctima y no su propio hogar, como había dicho en un comienzo. En el primer bloque, también, se había mencionado erróneamente la posibilidad de que hubiera dos rehenes, información que luego fue desmentida por una fuente oficial entrevistada en ocasión del móvil. 
que estaba atrincherado en su hogar tras recibir una denuncia por violencia de género [...] se entregó finalmente a la justicia".

Puede afirmarse que, en general, el eje narrativo se concentra en el rol del victimario que es figurado, exclusivamente, a partir de su identificación sociológica-laboral y, de modo secundario, con algunos otros apelativos vinculados a la misma: "efectivo policial"; "oficial de policía"; "uniformado"; "oficial primero"; "auxiliar oficial", entre otros. En conexión con esto, se convierte en el protagonista de la mayoría de las acciones relatadas y su lugar de victimario es, de hecho, absolutamente elidido. Asimismo, las acciones de las que es sujeto (en el sentido sintáctico del término) no están directamente referidas al delito por el cual se lo quiere detener. Abundan, así, frases como: "se atrincheró", "se negó al traslado", "no accede a entregar el arma", "pide garantías", "se asustó por la situación que estaba viviendo" y, finalmente, "accedió a entregarse". Lo "alarmante" de la "situación" está, entonces, dado por el atrincheramiento - que lo convierte en un "individuo armado" - y no por la violencia (de género) ejercida sobre la víctima. De esa manera, el acontecimiento delictivo es caracterizado de forma completamente vaga, atenuada y en condicional, a través de calificativos como "situación", "hecho", "situación delictual", "situación compleja", "conflicto", "situación [que] terminó bien" o, aún peor, "problema familiar"; pudiéndose, por tanto, asociar este tipo de procedimiento con aquello que Van Dijk (2006) denomina incompletitud relativa, toda vez que en la descripción de una situación "puede expresarse alguna información, y dejar de lado otra" (p. 334), en este caso, la que debería ser central.

Así, en lugar de utilizar los minutos de aire para priorizar el detalle de la causa cuyo desenlace es la detención del acusado (y su posterior atrincheramiento), el medio elige dedicar los últimos tramos de la información brindada a enlazar este acontecimiento con otro - "de similares características, al menos en algunos puntos" — sucedido el día anterior y en otra localidad de la provincia de Mendoza (Imagen 4). En este último, un "gendarme atacó a su mujer"; nuevamente, otro caso de violencia de género. Mediante esta estrategia de conexión de hechos - que se observa, incluso, en el procedimiento de pantalla partida - , el medio fuerza el enlace entre dos hechos distintos que son, de este modo, presentados "dentro de un conjunto que los unifique" (FERNÁNDEZ PEDEMONTE, 2001); promoviendo modelos situacionales que pueden devenir en modelos interpretativos.

Por su parte, la víctima - de género femenino y también policía - ocupa un lugar claramente relegado y siempre en función de su relación subordinada con el victimario — varón; se alude a la misma como "la mujer de este policía", "su esposa", "su pareja", "la mujer del auxiliar que está atrincherado". Solo una vez, en el último fragmento analizado, se la identifica como "la víctima de la violencia de género" y, por "razones de seguridad", no se menciona su nombre ni el del policía en cuestión, así como tampoco 
hay imagen alguna de sus rostros. Tal como ocurre en el caso del femicidio sucedido en Córdoba, la víctima es, en algunos casos, sujeto pasivo de la acción - "la mujer que fue víctima de violencia de género" - y, en otros, directamente objeto ("oficial que habría ejercido violencia de género con su pareja"14).

La forma de presentar a la víctima y al victimario de este acontecimiento tiene rasgos propios de lo que Bennett (2012) Ilama personalización de las noticias: se crea una historia alrededor de los actores y se omiten los contextos estructurales que dan lugar a las acciones, presentadas en términos anecdóticos. Es este un mecanismo que forma parte del procedimiento de dramatización de la noticia, que suele ir acompañado de una escasa contextualización de la información. Desde el paradigma crítico de los estudios de framing, Gitlin (1986) aporta una síntesis elocuente de la dinámica fragmentaria de los discursos de la información:

La noticia concierne al evento, no a la condición subyacente; a la persona, no al grupo; al conflicto, no al consenso; al hecho que avanza la nota, no al que la explica. Parte de este trato deriva de las normas para la cobertura de la desviación en general: la noticia periodística arquetípica es una nota sobre delito (p. 295).

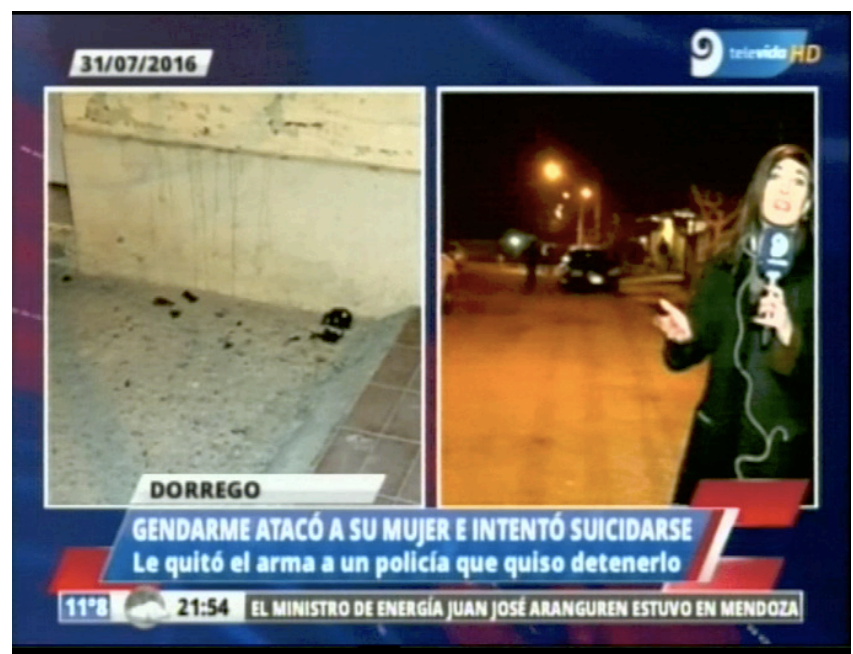

Fig. 4. Captura de TV nota Un policía acusado de violencia de género se atrincheró en su casa y se negó a entregarse. (Fuente: Canal 9 de Mendoza).

14 Nótese aquí el peculiar empleo de la preposición “con" que estaría en el lugar de otro término más apropiado, "contra", y se podría asociar, de este modo, a la idea también presente en el plano lingüístico verbal de "conflicto", término que es escogido por el medio para caracterizar la situación narrada. Según el diccionario de la RAE, en su sexta acepción, "con" significa "juntamente y en compañía". 


\section{Cierre}

El interés por comprender los modos en que son figurados las víctimas y los victimarios en las noticias sobre delito, violencia e inseguridad reside, justamente, en que el discurso de la información propuesto por los medios estudiados suele relatar los acontecimientos en términos dramáticos. Por tanto, es usual advertir que los productos mediáticos analizados enfoquen su relato en los personajes centrales de las acciones narradas (todos ellos desde un encuadre individual), en vez de explicar los contextos sociales en el que estas últimas tienen lugar.

Para cerrar este artículo, resta hacer algunas breves consideraciones respecto de las operaciones que se han señalado en el apartado anterior, en función de poder estudiarlas a futuro con mayor detenimiento y dilucidar el alcance de las mismas en un corpus mayor.

En primer lugar, puede decirse que no hay una correspondencia lineal ni directa entre quienes son asignados, en el discurso de los medios, en el rol de víctimas o victimarios, y quienes son agentes o pacientes de la acción delictiva o violenta propiamente dicha. Un rasgo que se puede ver en casi todas las notas analizadas.

En segundo lugar, se ha observado cierta relación entre los modos de figuración de los actores presentados como víctimas y victimarios y el sector socioeconómico al cual los mismos pertenecen. En este sentido, por ejemplo, en la configuración discursiva de los actores provenientes de sectores socioeconómicos medios o medios altos abundan las calificaciones sociológico-laborales, mientras que los pertenecientes a sectores más desfavorecidos del entramado social son caracterizados por apelativos moralizantes, no solo cuando son victimarios sino, muchas veces también, cuando cumplen el rol de víctimas.

En tercer lugar, emerge como un punto interesante sobre el cual seguir cavilando el lugar absolutamente relegado en el que se ubica a las mujeres cuando son víctimas de violencia de género; al menos en las dos últimas notas descriptas se observa que el epicentro de las mismas termina siendo el victimario varón. El discurso sexista no ha sido, en absoluto, un punto de partida en nuestra investigación, pero es posible aventurar que también en las noticias estudiadas se manifiesta un sesgo de género que revictimiza a la víctima.

En cuarto y último lugar, tanto la figuración de los personajes principales de la noticia como el modo en que es configurado el acontecimiento delictivo parecen, efectivamente, propiciar la construcción de un universo dicotómico de polaridad del tipo bien/mal o legalidad/ilegalidad. Semejante mirada simplista - bastante propia de lo que Lozano (2013) calificó como esa "tendencia de los medios a dar una explicación rápida de los hechos [mediante la cual] [...] automáticamente la ininteligibilidad del acontecimiento se hace inteligible depositándose en una narración" (s/p.) - muchas veces deriva en un sesgo de normalización, según el cual las instituciones - en particular, las estatales - están para reencauzar cualquier tipo de desviación, y en la propuesta de soluciones fundamentalmente punitivistas. 
Natalia Raimondo Anselmino es doctora en Comunicación Social por la Universidad Nacional de Rosario (UNR) e investigadora adjunta del CONICET. Se desempeña como docente en la Licenciatura en Comunicación Social en la UNR y en la Licenciatura en Diseño Gráfico de la Universidad Abierta Interamericana (UAI). Dicta, asimismo, cursos de posgrado en la UNR y otras universidades. Es miembro del Comité Académico del Centro de Investigaciones en Mediatizaciones (CIM) e investigadora afiliada al Centro de Estudios sobre Medios y Sociedad de Universidad de San Andrés y Northwestern University (MESO). Desarrolla tareas de investigación en el campo de la semiótica de los medios y las mediatizaciones, teniendo a la prensa y a las redes sociales en Internet como objetos privilegiados de estudio.

natalia_raimondo@hotmail.com

Natalia Aruguete es investigadora del CONICET y de la UNQ. Profesora de la UNQ. Doctora con mención en Ciencias Sociales y Humanidades por la Universidad Nacional de Quilmes (UNQ) y Magíster en Sociología Económica (IDAES-UNSAM). Ha realizado una estancia de investigación en la Universidad de Salamanca, España (2006). Es profesora de la Universidad Nacional de Quilmes y de la Universidad Austral. Su línea de investigación se centra en el estudio de las agendas política, mediática y pública en el diálogo entre medios tradicionales y medios sociales, desde las teorías de la Agenda Setting, el Framing y el Indexing. Se desempeña como colaboradora periodística especializada en Página/12 y Le Monde Diplomatique Ediciones Cono Sur.

nataliaaruguete@gmail.com

Francisco Hernando Arri es candidato a Doctor en Ciencias de la Información (Universidad Austral, Buenos Aires) y Máster en Comunicación y Educación (Universidad Autónoma de Barcelona). Dirige el área de Educación de la Facultad de Ciencias de la Educación y de la Comunicación Social de la Universidad del Salvador. Se desempeña como docente en las Universidades del Salvador, de Ciencias Empresariales y Sociales y Abierta Interamericana. Dicta cursos de posgrado en la Facultad de Humanidades y 
Artes de la Universidad Nacional de Rosario y en la Universidad Columbia (Paraguay). Investigador del Instituto de Investigación en Ciencias de la Educación y de la Comunicación Social en la Universidad del Salvador. Su área de investigación está referida a las tecnologías digitales, las nuevas mediatizaciones y las estrategias de lectura y navegación en dispositivos móviles. También investiga textualidades periodísticas desde la teoría de los discursos sociales y el análisis del discurso.

arripancho@gmail.com

\section{Referencias}

ADELSTEIN, A. Enunciación y crónica periodística. Buenos Aires: Ars, 1996.

ARUGUETE, N. (En prensa). Network-Activated Frames (NAF), Redefining Framing in a New Digital Era. En PETERS, M. A. \& HERAUD, R. (Org.). Encyclopedia of Educational Innovation, Springer Nature: Singapore, 2019

ARUGUETE, N. y RAIMONDO ANSELMINO, N.¿Héroe popular o asesino? Víctimas y victimarios en las noticias. En LetraP. Edición del 09/11/2018. Disponible en: https://www.letrap.com.ar/nota/201811-9-11-20-0--heroe-popular-o-asesino-victimas-y-victimarios-en-las-noticias?fbclid=IwAR1EHXAef 9lxgipE7jBPMWQMf52F8dvVp6iHShTX6bbM9aswfElwBu_SR4Y, 2018 Acceso: 15 de julio de 2019.

ARUGUETE, N., RAIMONDO ANSELMINO, N., ZUNINO, E., KOZINER, N. \& FABBRO, G.Matriz para el estudio de noticias televisivas sobre delito, violencia e inseguridad: una articulación teóricometodológica. Austral Comunicación, Buenos Aires, 7(2), p. 229-250, 2018.

BENNETT, W. L. News. The Politics of Illusion (9th Ed.). Illinois: Pearson Education Inc, 2012.

CALZADO, M. Ciudad segura. Vecindad, víctimas y gubernamentalidad. Notas sobre la campaña electoral del PRO en la Ciudad de Buenos Aires (2011). Ponencia presentada en las VII JORNADAS DE SOCIOLOGÍA DE LA UNIVERSIDAD NACIONAL DE LA PLATA "ARGENTINA EN EL ESCENARIO LATINOAMERICANO ACTUAL: DEBATES DESDE LAS CIENCIAS SOCIALES". Ponencia. p. 1-11, La Plata: Universidad Nacional de La Plata, 2012.

Inseguros. El rol de los medios y la respuesta política frente a la violencia de Blumberg a hoy. Buenos Aires: Aguilar, 2015.

DAMMERT, L. Violencia, crimen e inseguridad en América Latina. Revista Estudios Policiales, 6, p. 56-87, 2009.

ENTEL, A. La ciudad y los miedos. La pasión restauradora. Buenos Aires: La Crujía, 2007.

ENTMAN, R. M.Framing: Toward clarification of a fractured paradigm. Journal of Communication, 43(4), p. 51-58, 1993.

Projections of power: Framing news, public opinion, and US foreign policy. Chicago: University of Chicago Press, 2004.

FERNÁNDEZ PEDEMONTE, D. La violencia del relato. Discurso periodístico y casos policiales. Buenos Aires: La Crujía, 2001. 
FERNÁNDEZ, J.L y TOBI, X.Criminal y contexto: estrategias para su figuración. Revista LIS (Letra, Imagen, Sonido) Ciudad Mediatizada, Buenos Aires, Año II, nº 4, 2009.

FERREE, M. M., GAMSON, W. A., GERHARDS, J., \& RUCHT, D. Shaping Abortion Discourse. Democracy and the Public Sphere in Germany and the United States $\left(1^{\circ}\right)$. Cambridge: Cambridge University Press, 2002.

FOCÁS, B. M., \& KESSLER, G. Inseguridad y opinión pública: debates y líneas de investigación sobre el impacto de los medios. Revista Mexicana de Opinión Pública, (19), p. 41-58, 2015.

KESSLER, G. Miedo al crimen: campo de investigación y preocupación política. Oficios Terrestres, La Plata, 17, p. 27-37, 2005.

. El sentimiento de inseguridad. Sociología del temor al delito. Buenos Aires: Siglo XXI, 2009.

Ilegalismos en tres tiempos. En R. Castel, G. Kessler, D. Merklen, \& N. Murard (Eds.) Individuación, precariedad, inseguridad (pp. 109-165). Buenos Aires: Paidós, 2013.

KILLIAS, M. Précis de criminologie. Bern: Stämpfli, 1991.

KOZINER, N. Standing de las fuentes periodísticas en la política de medios argentina (2009 y 2016).

Cuadernos. info, (42), p. 101-118, 2018.

LAGOS, M., \& DAMMERT, L. Latinobarómetro: La Seguridad Ciudadana El problema principal de América Latina. Lima. Recuperado 3 de mayo de 2018, de http://www.latinobarometro.org/ documentos/LATBD_La_seguridad_ciudadana.pdf), 2018.

LOZANO, J. Entrevista realizada por RAIMONDO ANSELMINO, N. En Revista Ñ, 04/06/2013: Wikileaks bajo la lupa de la semiótica. Disponible en: https:/www.clarin.com/rn/ideas/Wikileakslupa-semiotica_0_SkBSEjvoPmx.html, 2013. Recuperado el 15 de julio de 2018.

MARTINI, S.Opinión pública, medios masivos y control social. ¿Los bárbaros están entre nosotros? En MARTINI, S. \& CONTURSI, M.E (eds). Comunicación pública del crimen y gestión del control social. Buenos Aires: La Crujía, p. 7-46, 2012.

MURATORI, M.; ESPÍNDOLA, S. Documento de Trabajo. Observatorio de la Deuda Social Argentina. Buenos Aires: Universidad Católica Argentina, 2016. Disponible en de http://www.uca.edu.ar/uca/ common/grupo68/files/2016-Observatorio-Documento-Victimizacion-Inseguridad-Subjetiva.pdf Acceso: 3 de mayo de 2018 .

REESE, S. D. The framing project: A bridging model for media research revisited. Journal of Communication, 57(1) , p.148-154, 2007.

SALAVERRIA, R., \& DESIDERI, L. L.El flujo continuo de noticias y sus efectos. En El nuevo diálogo social: organizaciones, públicos y ciudadanos (pp. 149-160). Valencia: Campgráfic, 2015.

SIGAL, S.; VERÓN, E.Perón o muerte. Los fundamentos discursivos del fenómeno peronista. Buenos Aires: Eudeba, 2008

SOZZO, M. Postneoliberalismo y penalidad en Argentina (2003-2014). En (Ed.), Postneoliberalismo y penalidad en América del Sur. Buenos Aires: CLACSO, p. 189-283 2016.

TRAVERSA, O.Mirando hacia atrás / mirando hacia adelante: discusión y conclusiones acerca de un recorrido por la prensa. En Cuerpos de papel. Figuraciones del cuerpo en la prensa 19181940. Buenos Aires: Gedisa, 1997.

VAN DIJK, T. Ideología. Una aproximación multidisciplinaria. Barcelona: Gedisa, 2006.

; TING-TOOMEY, S; SMITHERMAN, G.; TROUTMAN, D.Discurso, filiación étnica, cultura y racismo. En van Dijk (comp.) El discurso como interacción social. Estudios sobre el discurso II. Una introducción multidisciplinaria. Barcelona: Gedisa, 2000. 
VERÓN, E. La semiosis social. Fragmentos de una teoría de la discursividad. Buenos Aires: Gedisa, 1987. . El cuerpo de las imágenes. Bogotá: Norma, 2001.

Fragmentos de un tejido. Buenos Aires: Gedisa, 2004.

Artigo recebido em 10/06/2019

e aprovado em 30/07/2019. 